\title{
MÃO-DE-OBRA BARATA: O SOFRIMENTO NO TRABALHO DE ESTAGIÁRIOS
}

\section{CHEAP LABOR: THE SUFFERING IN INTERNS WORK}

\author{
Jéssica Syrio Callefi \\ Departamento de Engenharia de Produção - Universidade de São Paulo \\ São Paulo, SP, Brasil \\ Email: jessica.callefi@gmail.com
}

Gustavo Adolfo Ramos Mello Neto

Departamento de Psicologia - Universidade Estadual de Maringá

Maringá, PR, Brasil

Email: garmneto@gmail.com

\section{RESUMO}

As mudanças na forma de produção da manufatura, a partir da Revolução Industrial, implicaram diretamente na forma de realização do trabalho pelas pessoas. Mais recentemente, a adequação do homem ao trabalho começou a ser pensada para além do aspecto físico, incluindo-se a questão psíquica, verificando-se que todo trabalho pode causar prazer e sofrimento (DEJOURS, 2008). Nesta linha de pensamento, este artigo apresenta um estudo a respeito do sofrimento no trabalho de estagiários. Foram entrevistadas acadêmicas de diferentes cursos de graduação, objetivando estudar as percepções sobre o estágio por estas pessoas. Utilizou-se a teoria do sofrimento no trabalho de Dejours (2008, 2011, 2015) para analisar as entrevistas. Concluiu-se que o sofrimento no trabalho já se inicia nos primeiros contatos com a profissão almejada. Nas falas das entrevistadas foram encontrados elementos relacionados a defesas, humilhação, trabalho sem sentido, e desmerecimento da função de estagiário.

Palavras-chave: Estagiário. Sofrimento. Trabalho. Estratégias de defesa. Dejours.

\section{ABSTRACT}

The changes in the form of manufacturing production, based on the Industrial Revolution, directly involved in the way people work. More recently, man's suitability to work has begun to be thought beyond the physical aspect, including the psychic issue, verifying that all work can cause pleasure and suffering (DEJOURS, 2008). In this line of thought, this article presents a study about suffering in the work of interns. Academic from different undergraduate courses were interviewed, aiming to study perceptions about the internship by these people. The theory of suffering as proposed in Dejours' work $(2008,2011,2015)$ was used to analyze the interviews. It was concluded that suffering at work is already initiated in the first contacts with the desired profession. In the interviewees' statements, elements related to defenses, humiliation, meaningless work, and demereation of the role of intern were found.

Keywords: Intern. Suffering. Work. Defensive Strategies. Dejours. 


\section{INTRODUÇÃO}

O tema do trabalho tem se tornado central na sociedade atual, uma vez que a facilitação do acesso aos bens de produção de modo global requer a produção de bens de forma rápida e eficaz e este é o meio de produzir (PINTO, 2007). Ademais, com a inserção dos conceitos da racionalidade do trabalho, introduzidos a partir do taylorismo e seu conceito principal, a divisão do trabalho, a execução das tarefas para a produção de produtos se tornou mais fragmentada, distanciando-se da produção artesanal a qual os indivíduos estavam acostumados (KANAANE, 2007); consequentemente, uma nova maneira de pensar o trabalho inseriu-se na vida dos indivíduos.

Apesar do início do sistema taylorista ter ocorrido no final do século XVIII, seus procedimentos ainda são atuais, inclusive a forte cisão entre a questão física e psicológica do indivíduo. No entanto, sabe-se que o trabalho tem grande importância tanto nas dimensões materiais para o indivíduo, o qual necessita realizar tarefas em busca de sua subsistência; quanto psicológica, visto que o indivíduo interage com as pessoas e a cultura da organização a qual se insere (ANGELLA, 2015). Dessa forma, um maior entendimento acerca do trabalho e das relações que existem entre ele e o indivíduo permitem avanços teóricos e práticos dentro do assunto.

A temática do trabalho já foi discutido por diferentes paradigmas e autores, como: Marx (1849), quem discute o trabalho, de maneira geral, como força vital trocada por dinheiro; Arendt (2011) a qual distingue o trabalho em duas vertentes: o artesão (homo faber) e o operário (animal laboran), de forma que o artesão precisa realizar o trabalho como uma necessidade humana e o utiliza como caminho para a emancipação, enquanto o operário produz somente por obrigação ou alguma necessidade humana imediata; Dejours (2008; $2012^{a}$; 2012b; 2015), precursor dos estudos sobre a psicodinâmica e o sofrimento no trabalho, analisa a fundo a influência que o trabalho exerce sobre o indivíduo e como o mesmo lida com esta realidade. Embora exista uma gama de âmbitos para ser discutido dentro deste assunto, este trabalho foca no sofrimento no trabalho.

Dentro das pesquisas científicas, verifica-se a significância do tema, o qual aumentou em número de publicações nas áreas da influência do trabalho sobre os indivíduos nos últimos anos (MACHADO; MACÊDO; MACHADO, 2017). Mesmo com vários estudos avançando neste tema, entende-se que cada profissão tem suas particularidades e possibilidades de descobertas, bem como as fases da vida do indivíduo. Ademais, o sofrimento no trabalho pode ser compreendido de formas diferente a cada geração. Isso posto, uma destas áreas que foi pouco discutida até o momento é o trabalho do estagiário.

Os estagiários são acadêmicos que prestam um serviço para as organizações, depois de adquirir conhecimento teórico sobre o assunto, e são supervisionados por responsáveis pelo seu aprendizado, a fim de aprender a exercer a profissão a que desejam se dedicar. Além disso, o estágio é uma prática obrigatória na maioria dos cursos de graduação. Devido a inserção dos alunos cada vez mais cedo no ambiente acadêmico, os quais passam do ensino médio para a universidade direto ou com alguns anos de cursinho, muitas vezes estes indivíduos não tiveram uma experiência de trabalho, de forma que o estágio se torna o a primeira experiência de trabalho deles.

Os estagiários iniciam seu trabalho, ao menos supostamente, com o desejo de aprender e de poder auxiliar nas questões que a organização necessita, de acordo com sua bagagem teórica universitária; visando um período de experiência na área de atuação de sua graduação. Porém, nem sempre isto é vivenciado por 
estas pessoas. Assim, este estudo visa compreender quais são essas expectativas que não são supridas nos estágios entre outras questões que geram sofrimento no trabalho destes estagiários. Dito de outra forma, busca-se como objetivo geral desta pesquisa: compreender quais os fatores que mais causam o sofrimento no trabalho dos estagiários. Para isso traçou-se os seguintes objetivos específicos: a) saber quais eram as expectativas destes indivíduos em relação ao trabalho; b) saber como funciona a prática diária de trabalho do indivíduo; e, c) interpretar o sofrimento do indivíduo a partir de suas expectativas e de suas práticas.

Justifica-se este trabalho primeiramente pelos escassos estudos contemplando estagiários. E na vertente prática, espera-se que este trabalho venha a dar alguma contribuição, por pequena que seja, para uma melhor compreensão da realidade de trabalho dos futuros profissionais que necessitam realizar o estágio para sua formação como profissionais.

\section{REFERENCIAL TEÓRICO}

$\mathrm{O}$ trabalho apresenta diversos entendimentos de acordo com a sociedade em que se insere. $\mathrm{Na}$ sociedade grega, por volta do século $\mathrm{V}$, o trabalho estava relacionado às necessidades básicas do ser humano, como se alimentar e ter um lugar para dormir, não era uma atividade valorizada pela sociedade, além disso, era tido por algumas sociedades como uma forma de tortura (ENRIQUEZ, 1999; PINTO, 2007). A partir da Revolução Industrial Inglesa, no século XVIII, o trabalho se transformou em um símbolo da liberdade para os indivíduos, por sua capacidade de transformar a natureza e a sociedade (ENRIQUEZ, 1999; KANAANE, 2007).

Depois da Revolução Industrial Inglesa, a forma de produzir bens também se modificou. A produção passou de artesanal para produção em massa. Na produção artesanal, o trabalhador conseguia imprimir a sua subjetividade ao produto que estava sendo produzido, enquanto, na produção em massa, pela fragmentação das atividades do trabalho, o trabalhador não teria mais a possibilidade de colocar algo de si em sua produção de trabalho, tornando o trabalho sem sentido. Isso porque Organização Científica do Trabalho proposta por Taylor (1990) buscava eliminar a subjetividade das tarefas do trabalho, analisando o trabalho de maneira racional, almejando maior produtividade (LANCMAN; UCHIDA, 2003). Atualmente, o emprego - trabalho com vínculo empregatício, tomou um lugar central no modo de produção capitalista (BEATRIZ, 2010). Porém, este aspecto se tornou um dos grandes males da sociedade contemporânea, por destituir a subjetividade do trabalhador na realização das atividades (BEATRIZ, 2010) e considerar os indivíduos apenas como engrenagens para o funcionamento das fábricas.

Ainda no século XXI, a representação social do trabalho relaciona-se, primeiramente, como a subsistência para as pessoas, e depois, pode ser percebida como algo central da identidade das pessoas, englobando a aprendizagem, autonomia, reconhecimento e segurança (MORIN; TONELLI, 2007). Portanto, vê-se que o trabalho tem dupla importância na vida das pessoas: além de prover subsídios para a manutenção da vida, torna-se um elemento essencial de sua identidade.

Para Dejours (2012b, p. 38): "trabalhar é preencher a lacuna existente entre o prescrito e o efetivo". Ou seja, o indivíduo cria táticas e truques para realizar a tarefa prescrita para que o objetivo final seja alcançado conforme idealizado pelo próprio indivíduo ou por quem o prescreveu. Isso porque se o executor da tarefa seguisse a prescrição ao pé da letra, não conseguiria dar conta de seu encargo. Este fator é 
importante, visto que ao produzir algo ou realiza uma tarefa, o indivíduo tem a possibilidade de objetivar a sua subjetividade, ou seja, criar maneiras de realizar e produzir a partir do que idealizou pessoalmente. Dessa forma, por estar intimamente relacionado com o indivíduo, o trabalho pode suscitar entusiasmo e angústia, prazer e sofrimento (DEJOURS, 2012b).

Dejours (2008) também afirma que o trabalho, quando é somente prescrito e não se utiliza da criatividade humana, desumaniza os indivíduos. Dessa forma, não ter a compreensão do motivo da realização da tarefa e/ou acreditar que a tarefa é inútil, pode gerar sofrimento ao indivíduo. Ao contrário disso, o trabalho criado pelo próprio indivíduo, vem de encontro com a utilidade da realização da ação do trabalho. Conforme aponta Tweedie (2017), o trabalho pode auxiliar os indivíduos a realizarem suas aspirações dentro a organização em que estão inseridos.

Pelo fato do trabalho ser uma atividade necessária para a subsistência, o indivíduo, muitas vezes, se submete a trabalhos com riscos físicos e psíquicos. A artimanha psíquica para conseguir permanecer em um trabalho com riscos e aguentar o sofrimento gerado por ele é denominada de "estratégia de defesa" por Dejours (2012b). Dentro deste conceito entende-se que, de maneira inconsciente, o indivíduo passa a negligenciar os riscos para que possa continuar executando seu trabalho, como por exemplo: os sofrimentos de tristeza, frustração, dificuldade de dor, impotência e incapacidade, a que são submetidos (SANTOS; CORRAL-MULATO; BUENO; ROBAZZI, 2016).

Dejours (2015) considera que o sofrimento relacionado ao trabalho pode ser percebido de duas maneiras: insatisfação e ansiedade.

A insatisfação pode ser ocasionada pelos sentimentos de: (a) indignidade do trabalho, quando o indivíduo se submete a trabalhos maçantes, com sujeira, e despersonalizadores; (b) inutilidade do trabalho, que remete a falta de conteúdo significativo do trabalho para o indivíduo, ou seja, a importância da realização das atividades do trabalho para alcançar um objetivo final; (c) desqualificação profissional do indivíduo para ocupar cargos mais honrosos; e, (d) fadiga e cansaço gerados pela alta carga de trabalho (DEJOURS, 2015).

Quanto à ansiedade, esta é apresentada em três formas por Dejours (2015, p. 100):

(a) ansiedade relativa à degradação do funcionamento mental e do equilíbrio psicoafetivo, que diz respeito à despersonalização das pessoas, gerada a partir de seu próprio condicionamento mental, para conseguir manter os comportamentos esperados dentro da organização; (b) ansiedade relativa à degradação do organismo, gerada a partir dos riscos relacionados à saúde física do indivíduo; (c) ansiedade gerada pela "disciplina da fome", no qual os indivíduos se submetem às condições que ameaçam seu equilíbrio e funcionamento mental pelo motivo da sobrevivência.

Outros pontos levantados por Dejours (2012a) a respeito do mal estar que atinge as pessoas atualmente no mundo do trabalho são: desnivel entre o trabalho prescrito ao trabalhador e o trabalho efetivo realizado por esta pessoa, a falta do trabalho vivo, que é o acréscimo de atividades, realizado pelo próprio indivíduo, às atividades da prescrição do trabalho, a corporificação do trabalho, a falta de reconhecimento, a 
servidão voluntária, na qual os indivíduos realizam serviços que o seu senso moral desaprova e o sofrimento ético.

Apesar de tantas formas possíveis de sofrimento no trabalho, é perceptível que muitos indivíduos negligenciam os perigos de seus trabalhos. Para Dejours (2012b), essa atitude é inconsciente e funciona como uma estratégia de defesa para que o indivíduo consiga continuar trabalhando, as defesas são:

condutas paradoxais sobre como assumir os riscos, uma indisciplina em relação às medidas de prevenção e de segurança, a não manifestação pública da expressão do medo ao sofrimento e a obrigação de participar de demonstrações ostentatórias de desprezo e enfrentamento quanto ao risco, bem como a exibição de sinais exteriores da coragem, da resistência ao sofrimento, da força, da invulnerabilidade e da virilidade (DEJOURS, 2012b, p. 64).

O silêncio constante e não comentar os erros e problemas pode ser um efeito de medo que afeta o indivíduo e também a organização na qual está inserido (DORADO; SOLARTE, 2016). Vale ressaltar que os indivíduos buscam suprir três necessidades básicas quando estão em grupo, são elas: (a) inclusão, identidade, que está relacionada às expectativas que o grupo tem do indivíduo e o que o próprio indivíduo espera contribuir com o grupo, ou seja, uma função útil; (b) controle, poder e influência, que se apresenta na necessidade de o indivíduo controlar o entorno e sentir-se seguro; (c) aceitação e intimidade, que é a necessidade de se sentir aceito e incluso pelo grupo (SCHEIN, 1998).

Verifica-se que para ser aceito no grupo, ou seja, suprir uma necessidade básica, muitas pessoas se submetem aos trabalhos dentro de grupos, que podem ser maléficos para sua saúde física e psíquica. Isso porque, quando as necessidades de inclusão, controle e aceitação não são supridas, o indivíduo também pode iniciar um processo de sofrimento no trabalho.

Quando o estagiário encontra um lugar para trabalhar, ele também se insere em uma cultura diferente da que está acostumado, que contém pressupostos básicos e crenças que são compartilhadas por todos os seus membros (SCHEIN, 1988). A partir do momento em que esse novo membro se insere no grupo, precisa aprender sobre as normas e padrões de convivência.

Dessa forma, pela importância cultural dada ao trabalho na sociedade contemporânea (BEATRIZ, 2010), e no caso desta pesquisa, a obrigatoriedade da realização do estágio, o indivíduo tem tendência a ocultar os malefícios do próprio trabalho para poder conviver com o sofrimento, ocasionando riscos para sua própria saúde psíquica.

\section{MÉTODO}

Para obter uma análise aprofundada na percepção do indivíduo, optou-se pela pesquisa qualitativa neste estudo. Esta se apresenta como mais abrangente e profunda para a análise de seus objetos de pesquisa quando se trata da subjetividade, além de possibilitar que se utilize o contexto da realidade destes sujeitos para a observação e análise nos estudos (FONTANA; FREY, 2005). 
Para a coleta de dados, optou-se pela entrevista semiestruturada (DENZIN; LINCOLN, 2006), tendendo para uma entrevista não estruturada, uma vez que se deseja descobrir o que os sujeitos de pesquisa pensam sobre o seu trabalho e o sofrimento relativo ao seu trabalho, com liberdade para expressar a sua percepção do assunto e revelar algo de sua subjetividade. Dessa forma, na entrevista semiestruturada foram elaboradas algumas questões abertas com a função de servir de guia sobre o assunto a ser abordado, permitindo a fluidez da entrevista.

Fontana e Frey (2005) tecem algumas considerações acerca da entrevista semiestruturada e não estruturada, afirmam que o entrevistador deve conhecer bem o tema que deseja estudar, pois o entrevistado é mais livre para responder questões e dizer suas impressões a respeito do tema do que em entrevistas fechadas, podendo fugir do tema, assim o entrevistador deve guiar a entrevista para obter as informações que deseja. Fontana e Frey (2005) apresentam ainda alguns passos para a realização da entrevista que foram utilizados nesta pesquisa: (1) acessar o meio que está sendo estudado; (2) compreender a linguagem e a cultura dos respondentes; (3) decidir a melhor maneira de se apresentar; (4) localizar um informante; (5) ganhar a confiança do entrevistado; (6) estabelecer uma relação de abertura para a entrevista; (7) coletar o material através da entrevista, no caso, com a utilização de um gravador.

Decidiu-se por realizar uma pesquisa com pessoas que estagiam atualmente ou estagiaram recentemente, desde que o estágio fosse o primeiro contato que estas pessoas tiveram com um emprego, para ser possível coletar as primeiras impressões relativas ao trabalho por esses indivíduos. Para obter entrevistados para a pesquisa, foram abordadas pessoas provindas de diversas áreas do conhecimento e de diferentes universidades, as quais estivessem dispostas a colaborar com a pesquisa e se enquadrassem no requisito do primeiro emprego. Os entrevistados foram abordados em ambiente acadêmico e convidados a participar das entrevistas e assim, relatarem suas experiências para este estudo.

Vale ressaltar que esta pesquisa se interessa em trabalhar com a subjetividade dos entrevistados e não obter uma resposta global replicável sobre o tema do sofrimento do trabalho dos estagiários. Foram obtidas três entrevistas com cerca de quarenta minutos de duração. Compreende-se que o número de entrevistados, relativamente pequeno, conseguiu trazer elementos significativos para a realização da análise de seus relatos frente à teoria e responder aos anseios desta pesquisa.

Os nomes atribuídos às entrevistadas são fictícios por questão de sigilo de pesquisa. Alice cursou engenharia civil na Universidade Estadual de Maringá, na cidade de Maringá e as informações da entrevista são relacionadas a um estágio que teve duração de seis meses. Beatriz cursou farmácia na Universidade Estadual de Londrina e realizou um estágio de seis meses na cidade de Londrina. Cecília cursou medicina no Centro Universitário Ingá e falou de suas experiências sobre residência em diversos hospitais durante dois anos.

A partir das experiências trazidas pelas estagiárias através das entrevistas semiestruturadas, realizou-se uma análise de conteúdo destas entrevistas, categorizando os trechos das entrevistas de acordo com a teoria de sofrimento no trabalho de Dejours $\left(2008 ; 2012^{\mathrm{a}} ; 2012 \mathrm{~b} ; 2015\right)$ e os aspectos de cultura organizacional de Schein (1988), para poder analisar o sofrimento no trabalho destas pessoas.

Nas entrevistas, primeiramente fora questionado a respeito das expectativas dos indivíduos sobre o estágio antes de iniciá-lo e sobre a realidade que observaram e as diferenças entre a expectativa e a realidade. Questionou-se também a respeito das práticas realizadas e a relação de conhecimento e 
aprendizagem obtidos com a experiência do estágio. Com estes dados em mãos, foram categorizados os trechos da entrevista onde fora observado: defesas, práticas que traziam maiores sofrimentos, quebras de expectativas, aprendizagem, realização no trabalho.

\section{RESULTADO}

A fim de poder fazer parte de um grupo de profissionais e atuar na área da profissão escolhida, em diversos cursos universitários é necessário que o estudante conclua as disciplinas de seu curso e também participe dos estágios obrigatórios relacionados à atividade profissional que irá exercer futuramente.

O período do estágio é um tempo no qual os estudantes conhecem a prática das atividades e a aplicação das teorias aprendidas dentro da sala de aula. Também é um momento de confrontação do conhecimento teórico e prático, com a comprovação da utilidade dos conhecimentos teóricos aplicados na prática. Além disso, o estudante se depara com diversos problemas, conflitos e situações rotineiras do trabalho e tem a possibilidade de treinar e verificar a sua competência para resolver os problemas com a supervisão de profissionais mais experientes, conforme ressalta a estagiária Alice: "Querendo ou não, fazer estágio é testar se você é capaz de exercer a sua profissão ou não, certo?".

É perceptível que existe uma grande expectativa por parte dos estudantes para iniciar os estágios e aprender sobre o funcionamento prático da profissão. Cecília e Alice apresentam as suas expectativas antes da realização dos estágios e durante os estágios. Para elas, houve uma quebra de expectativa.

Quando a gente entra no curso de medicina, a gente não vê a hora de chegar ao internato, porque passamos quatro anos extremamente difíceis e imaginando como vai ser para colocar tudo isso (conhecimento teórico) em prática. Então a gente acha que vai entrar no quinto ano sendo 'o médico - o melhor médico da face da Terra', e que todas as pessoas serão legais, que vão te ensinar tudo e que você só vai fazer o bem para as pessoas. [...] A realidade é bem diferente. Porque você encontra pessoas muito diferentes de você, acho que esse é o ponto que mais dificulta quando você vai para um estágio. Porque você acha que todo mundo vai te tratar como você trata os outros e na verdade não é assim. (Cecília)

Quanto eu estava na graduação eu queria muito estagiar em obra, eu estava no terceiro e quarto ano e estava tendo aquelas matérias de construção civil, e eu achava chato ver na teoria, queria ver na prática. Eu queria estagiar em obra, então eu esperava muito de um estágio assim. [...] Acho que no começo de todo estágio você fica animado porque está aprendendo, depois vai ficando um pouco maçante. Por isso tem muita gente que troca muito de estágios. (Alice) 
Um ponto apresentado por Alice foi o do trabalho "maçante". Quando as atividades se tornam rotineiras e não estimulam a criatividade, tentem a se tornar maçantes e sem sentido. Isso pode ocorrer também pela atribuição de tarefas insignificantes ou divergentes da atribuição dos estagiários, o que causa também grande insatisfação nos estudantes. Alice ressalta a monotonia do trabalho e a atribuição de tarefas que não eram referentes ao setor de engenharia, como, por exemplo, tarefas de outros setores da empresa que estavam sobrecarregados, organização e arquivamento de papéis antigos e atividades burocráticas.

$\mathrm{Na}$ Empresa $\mathrm{X}$, o que me angustiava às vezes era serviços que nem tinham a ver com a engenharia. Porque até os três meses eu estava aprendendo as coisas, depois ficou monótono porque ficou repetitivo. Tudo repetitivo! E, às vezes, eu era solicitada para colar papeizinhos do RH nas paredes. (Alice)

Beatriz também conta da sua insatisfação em realizar trabalhos que eram atribuição de outros profissionais do laboratório de farmácia, mas que eram repassados para que os estagiários realizassem: "Eu tinha que fazer trabalho de técnico, era tão escravo que eu tinha que fazer trabalho de técnico. Muita falta de respeito!". Beatriz conta que não recebia nenhuma remuneração para realizar os trabalhos que eram atribuídos aos profissionais da área, no caso os técnicos do laboratório, apenas recebia almoço do restaurante universitário. "Era bem pesado também. Era um estágio, mas a gente fazia a rotina das pessoas do setor. Eu fiquei uns seis meses. Fiquei bastante! Porque eu só queria almoçar de graça". Sobre esse mesmo assunto, Cecília conta sobre a alta carga de trabalho que estava submetida, bem como a responsabilidade que lhe era designada.

A gente tem que ter contato com paciente, só que lá no Hospital A o fluxo é grande. Então assim, a gente se divide, uma quantidade $x$ de alunos para uma quantidade muito grande de pacientes, e a gente tem um tempo limitado, são só $6 \mathrm{~h}$ de estágio por dias, a gente tem um tempo limitado para fazer nossas funções. A gente tem pouco tempo para ter o contato com o paciente. E poder passar as informações. Então a gente estuda pouco, a gente toca serviço mesmo, e é normal porque alguém tem que fazer. E como a gente é interno, na hierarquia a gente é mais zoado, a gente tem que fazer o que eles mandam a gente fazer. (Cecília)

Alice, por sua vez, conta que percebia que seu trabalho era considerado mais uma mão-de-obra barata e que sabia que não existia um interesse por parte da Empresa $X$ em treinar os estagiários para contratos futuros.

$\mathrm{Na}$ Empresa $\mathrm{X}$ eu não sentia que o trabalho era importante, tanto que eu saí de lá. [...] Eu via que eles queriam alguém para arrumar as 'baguncinhas'. É diferente de uma empresa que pega os estagiários no intuito de ensinar, fidelizar e ficar com eles por lá. Eu via que por mais que eu fizesse um ótimo trabalho, desse o melhor de mim lá, eles não tinham interesse em me contratar. (Alice) 
Um fato interessante da percepção do estágio pelas entrevistadas foi a aparição dos termos: "escravo" e "escraviário" (um neologismo com as palavras "estagiário" e "escravo"), em todas as entrevistas. Remetendo a grande quantidade de trabalho atribuída, sem um balanceamento da carga de trabalho, e ao não recebimento de salário, ou recebimento de um valor simbólico. Isso é percebido na fala de Beatriz, que comenta: "Era um trabalho meio escravo, porque a gente não ganhava nada. A gente só ganhava certificado e almoço, mas não tinha incentivo de nada". Essa percepção também aparece nas falas de Alice e Cecília:

Também a questão de que a supervisora não se planejava muito para me passar as atividades e passava em cima da hora. Ás vezes eu passava a semana inteira sem ter uma atividade, estava lá ociosa, dai ela passava na quinta feira para eu entregar na sexta, e não dava tempo. E, ela acabava me cobrando horário extra pra eu estar indo lá, e eu não podia por causa das aulas. (Alice)

E no Hospital A os preceptores também não são médicos com didáticas, então eles querem que você toque serviço, eles não estão preocupados com seu aprendizado ou não, eles tocam muito serviço, você sai de lá com um estresse absurdo, porque você acha que não aprendeu nada, não está fazendo bem para ninguém, e não está fazendo nada da sua vida! (Cecília)

Nota-se também no trecho da entrevista de Cecília, que os principais responsáveis por orientar os estagiários nesta nova fase da profissão, que no caso da medicina são os médicos preceptores, nem sempre estão dispostos a ensinar e dedicar seu tempo de maneira a auxiliar os estudantes. Por vezes até utilizam sua posição de poder para humilhar os recém-chegados.

Tem muitas pessoas, muitos preceptores (médicos responsáveis por orientar os estagiários de medicina) principalmente, que acham que são melhores que você e daí eles te colocam para baixo de todas as formas possíveis. [...] Então jogaram a gente lá e a gente fica lá. Então as pessoas são bem hostis na maioria do tempo. Não todas, mas a maioria delas são bem hostis. E fica bem na cara que elas não querem você ali. (Cecília)

Em alguns casos, os estagiários chegam a ser humilhados, de acordo com o relato de Cecília.

E a preceptora que passava visita no leito do paciente, ela queria que você soubesse tudo de todos, assim extremamente rápido. E se você não soubesse, ela te humilhava no meio de todo mundo. Daí, gritava no corredor, umas coisas assim. Então a gente chegava meio tenso para trabalhar. (Cecília) 
Um ponto que chama a atenção na questão do sofrimento no trabalho são as condições precárias e hostis de trabalho, onde, não só os estagiários estão realizando suas atividades, mas todos os trabalhadores do setor. A falta de percepção da sujeira por parte dos funcionários que conviviam com o ambiente, pode ser compreendida como uma estratégia de defesa, a fim de conseguir realizar seus trabalhos sem se incomodarem com o ambiente.

Era uma condição precária. O pessoal trabalhava de chinelo. Os clínicos, técnicos eram super porcos. Eu achava assim que era uma "porquísse". Eu odiei esse estágio e nunca quis fazer micro (estudo da microbiologia). Porque era muito porco, mexer com bactéria e o povo comia em lugar perto. Tinha um lugar de comer que era do lado do laboratório. E, daí era bem ruim. (Beatriz)

Outra estratégia defensiva é encontrada no relato de Beatriz, que considera que o sofrimento gerado no estágio foi necessário para sua decisão de não querer realizar atividades relacionadas à prática do trabalho: "Foi bom para eu saber que eu não iria querer aquilo para a minha vida nunca mais".

Cecília, que considera que os estagiários que estão aprendendo atrapalham o setor e isso é em decorrência da falta de treinamento que despendem ao estagiário, pois os mesmos ficam perdidos na realização de suas atividades por falta de um direcionamento:

Tem alguns profissionais de outras áreas, como enfermagem, técnicos, que não gostam da sua presença ali, acham que você atrapalha de todas as formas possíveis. Atrapalhar a gente sabe que atrapalha, principalmente porque você chega em um lugar desconhecido, você não sabe o que você vai fazer. Até você pegar o jeito, claro que você tem muitas perguntas para fazer. Você precisa entender como é que funciona aquilo, e eles não tem paciência nenhuma para te explicar, e você fica largado e perdido lá. (Cecília)

A suposição de Cecília de que o ato de estagiar atrapalha os outros funcionários do setor pode ser considerada uma estratégia de defesa. De forma que não enxerga que o problema está na falta de direcionamento e não na presença dos acadêmicos no ambiente em que estão inseridos.

Quanto ao ambiente de trabalho e a cultura organizacional, Cecília conta como a mudança do estágio do Hospital A para o Hospital B mudou a sua visão sobre uma das áreas da medicina, a clínica médica, na qual Cecília detestava no Hospital A e passa a gostar muito no Hospital B.

$\mathrm{Na}$ verdade tem várias rotações, então tem as rotações que você gosta e as rotações que você detesta. Acho que lá no Hospital A por causa desses preceptores em específico de uma rotação, aí todo dia era uma tragédia ir para lá. Que era a parte da clínica médica. Que foi diferente no Hospital B, que eu adorava fazer a parte de clínica médica. No Hospital A não. Mas é por causa da pressão psicológica que eles faziam na gente, sabe? (Cecília) 
De acordo com Cecília, a diferença entre os dois hospitais estava na área de recursos humanos do hospital, ou seja, na forma de tratar as pessoas. Pois, as rotinas de trabalho dos dois hospitais eram bastante parecidas e o que mudava era apenas a maneira de tratar os internos, com mais paciência e atenção no Hospital B.

Verifica-se que as entrevistadas tinham consciência de que o estágio gerava algum sofrimento, mas ao mesmo tempo, se utilizavam das estratégias defensivas para justificar a sua realização, como: a obrigação para terminar o curso de graduação cumprindo os requisitos exigidos de currículo, os benefícios de auxílio financeiro ou alimentício, e a possibilidade de ter as primeiras experiências com o trabalho.

As estagiárias reconhecem que precisam realizar o estágio, que este momento é importante para conhecer e começar a praticar a profissão que escolheram e que recebem ajuda para aprender e realizar as tarefas no novo ambiente de trabalho. Conforme ressalta Alice: "Ainda assim, para gente aprender, para o seu crescimento profissional pessoal é bom". Do mesmo modo Cecília também aponta alguns benefícios: "Em compensação, tem procedimentos que os preceptores deixam a gente fazer, que é o que a gente realmente quer fazer. Mas é tudo supervisionado, nós não fazíamos os procedimentos mais elaborados sozinhos".

Sabe-se que os hospitais escola e empresas de diversos ramos participam de um convênio com as universidades e faculdades, e dessa forma, é obrigação da organização que oferece o estágio promover um ambiente de aprendizado para eles. Ou seja, recebem os estagiários, que podem auxiliar de alguma forma no trabalho, mas em contrapartida devem fornecer informações para que os mesmos consigam atuar de maneira eficiente. Ademais, o estágio pode causar certa ansiedade nos estudantes, visto que o fracasso nem sempre é compreendido como uma parte do crescimento, mas como uma deficiência pessoal ou da formação do conhecimento. Este tipo de fracasso pode gerar traumas ou fortalecer a vontade de permanecer na profissão, quando superado.

\section{DISCUSSÃO}

A relação de trabalho de estágio contém dois atores: a empresa que contrata e o estagiário que oferece o seu serviço. A empresa recebe um profissional que não tem sua formação completa ainda e oferece um campo de estudo para que o acadêmico possa experimentar como funciona o trabalho. Por essa razão, entende-se que a empresa não precisa remunerar o estagiário da mesma forma que a um profissional formado, já que recebe um serviço de um trabalhador não graduado e o auxilia nesta formação.

Ressalta-se que a empresa gasta seus recursos de tempo e pessoal para o treinamento dos estagiários, porém, o que se discute é que em troca a empresa recebe a mão-de-obra e o conhecimento teórico que o estagiário já tem, obtendo benefícios e remunerando de maneira desconforme. Pois, o estagiário possui alguma carga teórica e, ademais, o conhecimento da vida prática que é utilizado para a realização das demandas de trabalho da empresa.

Assim, o vínculo entre o estagiário e a empresa começa a ficar desproporcional na medida em que o estagiário avança em seu conhecimento, dá bons resultados para a empresa, mas não é reconhecido e, frequentemente, não é remunerado de acordo com o benefício que proporciona. Verifica-se que o que ocorre é a utilização destas pessoas como mão-de-obra barata, simplesmente como uma maneira de economizar os recursos da empresa. 
Pela obrigatoriedade de cumprimento do tempo de estágio como uma disciplina curricular, as estudantes se veem obrigadas a se submeterem a trabalhos que nem sempre estão relacionados ao trabalho da profissão, ou ainda que Ihes causem enormes desgastes. Para isso, recebem algum valor financeiro simbólico, como a alimentação, ou simplesmente uma carta de comprovação das horas cumpridas para anexar ao currículo e poder, enfim, finalizar o curso de graduação.

É interessante notar, que o trabalho é uma atividade social e coletiva, porém, apenas uma das entrevistadas tratou sobre o assunto das equipes de trabalho, e as três consideraram o estágio por um âmbito mais pessoal. Verifica-se que as estagiárias trataram o trabalho como um desafio que deveria ser superado apenas por si e não em um coletivo de pessoas que deveriam se ajudar mutuamente. Essa falta de envolvimento e a hostilidade que são tratadas e tratam a empresa, torna-se um conflito nocivo para o entendimento geral do trabalho. Afinal, entende-se que uma organização é um sistema que utiliza pessoas para a realização de um fim. Dessa maneira, compreender qual seu papel para o resultado final da organização é de fundamental importância para o funcionamento geral da empresa e bem estar dos funcionários.

Nas entrevistas foi possível compreender que o estágio é entendido apenas como um meio para alcançar o diploma, e não um fim, já que as três entrevistadas não acreditavam que seriam efetivadas nos seus estágios. Esse aspecto pode explicar a falta de envolvimento com o pessoal do trabalho, de forma que as entrevistadas compreendem a realização do trabalho como uma competência pessoal primeiramente, uma prova final para verificar se estão prontas, como profissionais, para atuarem no mercado, sem o interesse em estabelecer relações.

Ademais, verifica-se que as estagiarias negligenciam o sofrimento gerado pelo estágio, não raro, utilizando estratégias defensivas de Dejours (2012b). Porém, vale discutir se vale a pena esclarecer para a pessoa que algumas de suas ações são defesas. Aguentariam o sofrimento psíquico gerado pela compreensão dessa nova realidade? De qualquer forma, acredita-se que apenas o reconhecimento da realidade gera a oportunidade de escolha em permanecer ou não em um ambiente nocivo, ou agradável.

Unindo a suposição de que o estágio bem cumprido depende da adequação do indivíduo ao trabalho com as estratégias defensivas que o próprio cria, tem-se que o indivíduo não percebe o quanto o estágio pode estar fazendo mal para sua saúde psíquica e ainda pode ter uma impressão errada sobre a profissão que pretende exercer futuramente. Dessa forma, é imprescindível que se discuta e se trate os problemas de sofrimento no trabalho, ainda mais tendo em conta que estes são, provavelmente, os primeiros contatos dos estagiários com a profissão que exercerão no futuro.

\section{CONCLUSÕES}

Este estudo se propôs a discutir as expectativas dos estagiários frente ao tema do trabalho e os sofrimentos gerados por ele. As entrevistas convergiram para alguns fatores chave, que relacionaram o sofrimento no trabalho dos estagiários com: insatisfação, inutilidade do trabalho, humilhação, trabalho sem sentido, desmerecimento da função (DEJOURS, 2015), a vontade de contribuir com o grupo e não conseguir, e de não se sentir útil (SCHEIN, 1998). 
Compreendeu-se que as estagiárias tinham grandes expectativas que não se mostraram na realidade. Em um primeiro momento, existia a euforia da descoberta no trabalho, o vislumbre da possibilidade de um emprego (BEATRIZ, 2010), a possibilidade de aquisição de conhecimento e a importância da realização do estágio como uma forma de trabalho na área de formação antes da obtenção do diploma. Porém, com o passar do tempo, os trabalhos ficavam monótonos, sem objetivo de aprendizagem e desgastantes. Esse fator pode estar relacionado ao fato de as empresas não terem clareza a respeito das funções do trabalho do futuro profissional e nem um plano de crescimento e acompanhamento do desenvolvimento do mesmo.

Os entrevistados contaram sobre as suas práticas diárias, e neste ponto, foi possível observar, não só como os entrevistados realizavam suas tarefas, mas como as observaram e o trabalho e como se sentiam em relação a ele. Com isso, foi possível interpretar o sofrimento do indivíduo a partir de suas expectativas e de suas práticas.

Como contribuição teórica, verifica-se que já nos primeiros contatos com o trabalho podem surgir as estratégias de defesa (DEJOURS, 2015). Estas estratégias podem estar relacionadas com o fato de se ter despendido grande energia para a conclusão de um curso universitário, e ao fim do percurso, quando estes formandos se deparam com o tralho de sua futura e profissão, precisam negligenciar para si mesmo os sofrimentos psíquicos que o mesmo gera, a fim de manterem-se no trabalho, sem questionar se este é ou não um ambiente saudável. 


\section{REFERÊNCIAS}

Angella, M. Work, recognition and subjectivity: Relocating the connection between work and social pathologies. European Journal of Social Theory, v. 19, n. 3, p. 340-354. 2015.

Arentd, H. A condição humana. Tradução: Roberto Raposo. Rio de Janeiro: Forense Universitária, 2011.

Beatriz, M. Z. O trabalho, a repressão e o mal-estar do trabalhador: algumas reflexões. Rev. Mal-Estar Subj. [online], v. 10, n. 4, p. 1107-1130, 2010. Disponível em: <http://pepsic.bvsalud.org/scielo.php?script=sci_arttext\&pid=S1518$61482010000400003>$.

Dejours, C. A loucura do trabalho: estudo de psicopatologia do trabalho. 6a ed. São Paulo: Cortez-Oboré, 2015.

Dejours, C. Christophe Dejours: da psicopatologia à psicodinâmica do trabalho. Brasília: FIOCRUZ, 2008.

Dejours, C. Psicodinâmica do Trabalho e Teoria da Sedução. Psicologia em Estudo, v. 17, n. 3, p.363-371, 2012a. Doi: http://dx.doi.org/10.1590/S1413-73722012000300002.

Dejours, C. Trabalho Vivo (Vol. 1). Tradução de Franck Soudant. Brasília: Paralelo 15, $2012 b$.

Denzin, N. K.; L. Y. S. Introdução: a disciplina e a prática da pesquisa qualitativa. In: Denzin, N. K., Lincoln, Y. S. (Org.). O planejamento da pesquisa qualitativa: teorias e abordagens. $2^{\mathrm{a}}$ ed. Porto Alegre: Artmed, p. 15-41, 2006.

Dorado, C. B.; Solarte, M. G. Efectos del miedo en los trabajadores y la organización. Estudios Gerenciales, v. 32, n. 1, p. 60-70, 2016. Doi: https://doi.org/10.1016/j.estger.2015.10.002.

Enriquez, E. Perda do trabalho, Perda da identidade. Caderno da Escola do Legislativo, v. 5, n. 9, p. 53-73, 1999. Disponível em: <https://dspace.almg.gov.br/handle/11037/1062?locale=en>.

Fontana, A.; Frey, J. H. The interview: from neutral stance to political involvement (3th ed.). In N. K. Denzin \& Y. S. Lincoln (Org.), The sage handbook of qualitative research (pp. 695-727). London, England: Sage, 2005.

Lancman, S.; Uchida, S. Trabalho e subjetividade: o olhar da Psicodinâmica do Trabalho. Cadernos de Psicologia Social do Trabalho, v. 6, n.1, pp. 79-90, 2003.

Machado, L. S.; Macêdo, K. B.; Machado, M. R. R. Diagnóstico de pesquisas internacionais em psicodinâmica do trabalho no Brasil. Psicologia,Saúde \& Doenças, v. 18, n. 1, p. 69-84, 2017.

Marx, K. Trabalho assalariado e capital. Lisboa: Avante, 1849. Disponível em: https://www.marxists.org/portugues/marx/1849/04/05.htm

Morin, E.; Tonelli, M. J. O trabalho e seus sentidos. Psicologia \& Sociedade, v. 19, n. 1, p. 47-56, 2007. Doi: http://dx.doi.org/10.1590/S0102-71822007000400008.

Santos, J. L. D., Corral-Mulato, S., Bueno, S. M. V., Robazzi, M. L. do C. C. (2016). Feelings of nurses faced with death: pleasure and suffering from the perspective of psychodynamics of Dejours. Invest. Educ. Enferm., v. 34, n. 3, p. 511-517, 2016. Doi: doi:10.17533/udea.iee.v34n3a10.

Schein, E. La cultura empresarial y el liderazgo: una visión dinámica. Barcelona, Espanha: Plaza \& Janes, 1988.

Taylor, F. W. Princípios da administração científica. Tradução: Arlindo Vieira Ramos. $8^{\circ}$ ed. São Paulo: Atlas, 1990.

Tweedie, D. The Normativity of Work: Retrieving a Critical Craft Norm. Critical Horizons, v. 18, n. 1, p. 66-84, 2017. 